\title{
The Emerging Trade in Donkey Hide: An Opportunity or a Threat for Communities in Kenya?
}

\author{
Gemma Carder ${ }^{*}$, Oscar Ingasia ${ }^{2}$, Evans Ngenoh ${ }^{2}$, Samuel Theuri ${ }^{3}$, Desmond Rono ${ }^{3}$, \\ Philemon Langat ${ }^{2}$ \\ ${ }^{1}$ Brooke, London, UK \\ ${ }^{2}$ Brooklyn Economic Consulting Ltd., Nairobi, Kenya \\ ${ }^{3}$ Brooke (East Africa), Nairobi, Kenya \\ Email: ^gemma.carder@thebrooke.org, admin@becoconsulting.com,ingasiaoa@gmail.com,ken.ngenoh@gmail.com, \\ samuel.theuri@thebrookeeastafrica.org,desmond.rono@thebrookeeastafrica.org
}

How to cite this paper: Carder, G., Ingasia, O., Ngenoh, E., Theuri, S., Rono, D. and Langat, P. (2019) The Emerging Trade in Donkey Hide: An Opportunity or a Threat for Communities in Kenya? Agricultural Sciences, 10, 1152-1177. https://doi.org/10.4236/as.2019.109087

Received: August 7, 2019

Accepted: September 15, 2019

Published: September 18, 2019

Copyright $\odot 2019$ by author(s) and Scientific Research Publishing Inc. This work is licensed under the Creative Commons Attribution International License (CC BY 4.0).

http://creativecommons.org/licenses/by/4.0/

\begin{abstract}
Donkey hides are used in a form of Traditional Chinese medicine called ejiao, the demand for ejiao is currently so high the global donkey population is currently in decline. Africa's donkey population is considered a key source for the trade, with Kenya being highlighted as being particularly affected. In Kenya donkeys play a vital contribution to people's livelihoods; this study aimed to explore the potential impact of the donkey hide trade on small holder farmer's livelihoods. The study was conducted in five counties in Kenya; data was collected using household survey questionnaires, focus group discussions and key informant interviews. When household survey participants $(n=421)$ were asked if the number of donkeys in their herd had decreased within the last two years $34.2 \%(n=144)$ reported a decrease, of those $43.8 \%(n=63)$ reported the selling of donkeys as the primary cause of reduction in herd size. Increased money spent on the transportation of farm produce, water and firewood was the most frequently reported effect of the loss of donkeys $(62.5 \%, n=263)$. Some focus group discussion participants said that they had previously sold their donkeys to raise money for school fees, likewise $43 \%(n=97)$ of focus group discussion participants said that they would sell their donkeys to pay medical bills. Results from the study suggest that small holder farmers are choosing to sell their donkeys for an instant boost in income, but long-term this is unlikely to be a sustainable livelihood option.
\end{abstract}

\section{Keywords}

Donkey Hide Trade, Kenya, Livelihoods, Traditional Chinese Medicine, 
Ejiao, Working Equids

\section{Introduction}

In many low- and middle-income countries equids make a vital contribution to people's livelihoods [1] [2]. Working equids support people's livelihoods in a range of sectors including construction, agriculture, tourism and public transport [1] [3]. Research conducted in India, Pakistan, Kenya and Ethiopia found that equids were ranked by women as their most important livestock, helping with household tasks and providing regular income [4]. The role of donkeys varies and is dependent upon the communities in which they live and work [5]. Traditional roles have included ploughing, riding, carrying packs, pulling carts and a smaller role in entertainment and food production [5]. Across Africa donkeys are commonly used for a range of work, they are often owned by smallholder farmers, pastoralists and small-scale entrepreneurs in the transport sector [3]. For example, in Ethiopia, which has one of the largest equine populations globally [1], donkeys are used in both urban and rural areas to transport goods from markets [6]. In Ethiopia's capital Addis Ababa, donkeys are commonly used to carry produce from rural areas to markets in the city [6]. A study which explored the economic contribution of donkeys to households living on the outskirts of Addis Ababa, found that 39\% of households who had recently acquired a donkey stated that their income had improved [6]. Households also said that they felt relief from the burden of carrying firewood and water; longer term impacts included children being released from their daily chores, and therefore having the opportunity to go to school [6]. Similarly, in Mali a survey of donkey owners found that donkeys provide an important economic contribution to people's livelihoods. The study found that $67 \%$ of donkey owners had an average monthly income of (US \$167), whilst the average monthly income per capita is (US \$55) [7].

In addition to their role as working animals, for centuries donkey meat and milk has been consumed. In Africa within some communities eating donkey meat is seen as taboo, whereas in some it is seen as an affordable source of animal protein [5]. In recent years (particularly in Europe) there has been a rapid increase in the use of donkeys as a source of meat and milk [2]. Although consumption of donkey milk is not a new concept, the number of donkey dairies has increased in Italy, Turkey and Serbia [2]. Recently a Serbian donkey dairy farmer has made news by producing cheese made from donkey milk [8]. The cheese, named pule, has been labeled as the world's most expensive cheese and sells for up to $£ 880 / \mathrm{kg}$ per kilo [8]. Donkey meat is also a lucrative product in China, Denmark, Germany and France [9]. The donkey meat and milk industry reportedly has helped increase population numbers of rare breeds in Europe which were facing extinction [8]. 
Within the Asian market an area that has dramatically increased is the use of donkey hide products [2] [5]. Donkey hides are used in a form of Traditional Chinese medicine (TCM) called ejiao. The hides are boiled to produce a firm gel which is dissolved in hot water or alcohol and is used in food drink and beauty products [8]. Ejiao is believed to have a variety of health benefits including improving blood circulation and treatment for reproductive problems [5] [8].

TCM dates back more than 5000 years [10]. In addition to the use of donkey hides, derivatives from a wide range of wild animal species are commonly used [11]. It has been reported that in China 12,772 resources are used in the manufacture of TCM, of these 1574 are derivatives from animals [12]. To meet market demand, many populations of wild species commonly used in TCM have declined, raising concerns that many aspects of wildlife trade are not sustainable [11] [13] [14] and also pose a serious animal welfare threat [13]. Species of wildlife rapidly in decline and often in the media's "spotlight" include rhinos, tigers and pangolins [15] [16] [17]. Derivatives from these animals are used in various TCM products including tonics, powders and wines and are believed by consumers to help treat a range of health conditions [13].

The demand for ejiao is currently so high, the global donkey population is currently in decline [2], with many working donkeys in low-and middle-income countries being used in the trade [2]. Africa's donkey population is considered a key source for the trade [5], with donkeys been slaughtered and traded in Niger, Burkina Faso, Nigeria, Tanzania, South Africa, Ethiopia and Uganda and Kenya [18]. Over the last few years donkey hides exported from sub-Saharan Africa to China have reportedly increased [2] [5]. In 2016, trade from sub-Saharan Africa to China represented $25 \%$ of the trade compared to just $2.3 \%$ in 1985 [5]. Kenya has been highlighted as a country particularly affected by the trade. This could be related to the legalization of donkey slaughter for the meat trade and the subsequent opening of two slaughterhouses in 2013 and 2014 [18]. Linked to the increased demand, in low-and middle-income countries the price of donkeys has increased, this has reportedly resulted in large numbers of working donkeys being slaughtered for the purposes of their skin and meat being exported to China [2] [5]. Ejiao can sell for up to $£ 300$ per $\mathrm{kg}$ [5]. The slaughter and processing of donkeys to meet this demand has resulted in welfare concerns in relation to the housing, transportation and slaughter of donkeys, as well as concerns focused on zoonotic disease transfer and the transmission of infectious diseases between animals [2]. Since January 2019, there have been reports of disease (likely equine influenza) outbreaks affecting donkeys across several West African countries. The World Organisation for Animal Health (OIE), has suggested that the unregulated trade and movement of donkeys may have contributed to this outbreak [19].

Despite the critical role of donkeys in supporting livelihoods, currently there is little data on how the growth of the donkey hide trade has affected small holder farmer's livelihoods. This study therefore aimed to explore the contribution of 
donkeys to livelihoods of smallholder farmers (farmers who typically own $<5$ acres of land) in Kenya and the potential impact that the donkey hide trade has on their livelihoods.

\section{Materials and Methods}

\subsection{Ethics}

Ethical approval was gained from Brooke's Animal Welfare and Ethical Review Body.

\subsection{Subjects and Study Location}

The study was conducted between 13 August and 24 August 2018 in five counties in Kenya; these were Kitui, Narok, Nyandarua, Kirinyaga and Bungoma. The study sites were chosen based on the high number of donkeys used by small holder farmers in these counties. Quantitative data was collected using structured household survey questionnaires (household defined as people who dwell under the same roof). Inclusion criteria for participants were previous and current donkey owners. Households were randomly selected from two sub-counties within each of the five selected counties. All sub-counties were listed in an excel spreadsheet and given numbers, using excel random generator, the sub-counties were randomly selected. In total 421 participants (18 years of age and above) were interviewed $(\mathrm{M}=251, \mathrm{~F}=170)$ (Table 1). Qualitative data was collected during focus group discussions (FGDs) and key informant interviews (KIIs). In total 33 FGDs and 48 KIIs were conducted $(\mathrm{M}=178, \mathrm{~F}=83)$. The majority of FGD participants were farmers (65.6\%) followed by transporters (8\%) and business owners (6.7\%). For the key informant interviews government leaders and county government representatives were interviewed (Table 2).

\subsection{Procedure and Data Collection}

Quantitative data were collected using a structured questionnaire (Supplementary Material 1), which was administered among randomly selected households. Data was collected using KoBoToolBox (mobile phone data collection tool); this involved entering the survey questions onto the platform. In each county the

Table 1. Number of household survey participants in each county.

\begin{tabular}{cc}
\hline Counties & Number of household survey participants \\
\hline Kitui & $124(29.5 \%)$ \\
Kirinyaga & $52(12.4 \%)$ \\
Nyandarua & $90(21.4 \%)$ \\
Bungoma & $50(11.9 \%)$ \\
Narok & $105(24.9 \%)$ \\
Total & 421 \\
\hline
\end{tabular}


Table 2. Number of FGD and KII participants in each county.

\begin{tabular}{cccc}
\hline \multirow{2}{*}{ Counties } & \multicolumn{2}{c}{ Focus group discussions (FGDs) } & Key informant interviews (KIIs) \\
\cline { 2 - 4 } & $\begin{array}{c}\text { Number of } \\
\text { FGDs }\end{array}$ & $\begin{array}{c}\text { Number of } \\
\text { participants }\end{array}$ & Number of KIIs \\
\hline Kitui & 7 & 49 & 9 \\
Kirinyaga & 7 & 49 & 8 \\
Nyandarua & 7 & 46 & 6 \\
Bungoma & 5 & 36 & 6 \\
Narok & 7 & 44 & 37 \\
Total & 33 & 224 & \\
\hline
\end{tabular}

questionnaires were administered by $7-8$ enumerators to the household head or spouse. Interviews were conducted in participant's homes. Where possible interviews were conducted in English; enumerators provided translation to participants who did not understand or speak English. Qualitative data collected through FGDs and KIIs were conducted at pre-arranged locations and were conducted in Swahili and English (Supplementary Material 2). FGDs consisted of 5 - 7 participants per group and lasted approximately two hours. All discussions and interviews were transcribed into English for later analyses.

All participants were informed of the objectives of the study and were given the choice to opt in or out. Those who agreed to be interviewed or participate in a FGD were asked to read and sign a consent form prior to participation.

\subsection{Data Analyses}

Quantitative data were downloaded from KoBoToolbox, and analysed using pivot tables and descriptive statistics in Excel. For the qualitative data (FGDs and KIIs), key themes/issues were identified (Table 3) themes were cross-cutting across all of the FGDs and KIIs. Each transcript from each FGD and KII were reviewed. The number of times a theme was discussed during each FGD/KII was recorded. For example, for a FGD comprising of 7 participants, if 5 participants said they were aware of the donkey hide trade a score of 5 was given to that FGD for that particular issue. Similarly if during a KII the interviewee said they were aware of the donkey hide trade a score of 1 would be given or 0 if they did not discuss their awareness of the trade. Using Excel descriptive statistics relating to the number of participants discussing each theme/issue were produced for the FGDs and KIIs (separately).

\section{Results}

\subsection{Household Survey (Quantitative Data)}

The majority of household survey respondents were smallholder farmers $(81.5 \%)$, of those $92.7 \%$ reported that they reared donkeys as part of their livestock. The median size of the respondent's household was five (range $1-11$ ), and 
Table 3. Description of themes used for analyses of transcripts from the FGDs and KIIs.

\begin{tabular}{|c|c|}
\hline Theme & Description \\
\hline Food security & $\begin{array}{l}\text { Contribution of donkeys to food production, including income } \\
\text { generation used to purchase food. }\end{array}$ \\
\hline Poverty & Effect of sale/loss of donkey on poverty. \\
\hline Education & $\begin{array}{l}\text { Indirect contribution of donkeys to education, including the sale of } \\
\text { donkeys to pay school fees. }\end{array}$ \\
\hline Gender & Ownership and use of donkeys among men and women. \\
\hline $\begin{array}{l}\text { Trade in } \\
\text { donkeys }\end{array}$ & $\begin{array}{l}\text { Factors which influence small holder farmer's decision to participate in } \\
\text { the donkey hide trade. }\end{array}$ \\
\hline $\begin{array}{l}\text { Awareness of } \\
\text { donkey hide trade }\end{array}$ & $\begin{array}{l}\text { Level of awareness of the donkey hide trade and general opinion } \\
\text { on the trade. }\end{array}$ \\
\hline Insecurity & Relationships between donkey hide trade and income security. \\
\hline $\begin{array}{l}\text { Elderly and } \\
\text { vulnerable }\end{array}$ & Effects of the loss/sale of donkeys on elderly and vulnerable groups. \\
\hline Income & Contribution of donkeys to income generation. \\
\hline $\begin{array}{l}\text { Domestic use of } \\
\text { donkeys }\end{array}$ & Degree to which donkeys are used for domestic chores. \\
\hline Policy/legislation & $\begin{array}{l}\text { Awareness and views of policies and legislation in relation to the donkey } \\
\text { hide trade in Kenya. }\end{array}$ \\
\hline
\end{tabular}

the median number of donkeys owned was 2 (range 1 - 15).

Across all five counties, the median purchase price of a donkey was 10,000 KES (98 USD; range 1000 - 20,000 KES). The median purchase price (KES) at each county was as follows: Kitu, 10,500; Narok, 13,000; Nyandarua, 9500; Kirinyaga, 9500 and Bungoma, 10,500.

The primary reported use of donkeys was for domestic chores only ( $n=208$, $49.4 \%)$, followed by commercial use only $(n=111,26.3 \%)$ and both commercial and domestic use $(n=94,22.3 \%)$. The primary activity that respondents used their donkey(s) for was carrying water (85.7\%) (Figure 1).

When participants were asked if they were aware of the donkey hide trade 92.6\% stated that they were aware of the trade. Of those that stated that they were aware of the trade $70.9 \%(n=390)$ said that the trade had been in operation in their community for more than two years, $30.3 \%$ believed it had been in operation for $1-2$ years, and $7.9 \%$ stated the trade had been taking place for less than one year. When participants were asked if the number of donkeys in their herd had decreased within the last two years $32.5 \%$ stated an increase, $34.2 \%$ reported a decrease and $33.3 \%$ said there had been no change. Of those that described a decrease $(n=144), 43.7 \%(n=63)$ stated that selling donkeys was the primary cause of the reduction in herd size (Figure 2).

When participants were asked if the donkey hide trade had affected their income, 57\%, reported that their income had been affected. Of those that said that there was an effect, $64.6 \%(n=240)$ stated that their income had initially increased 


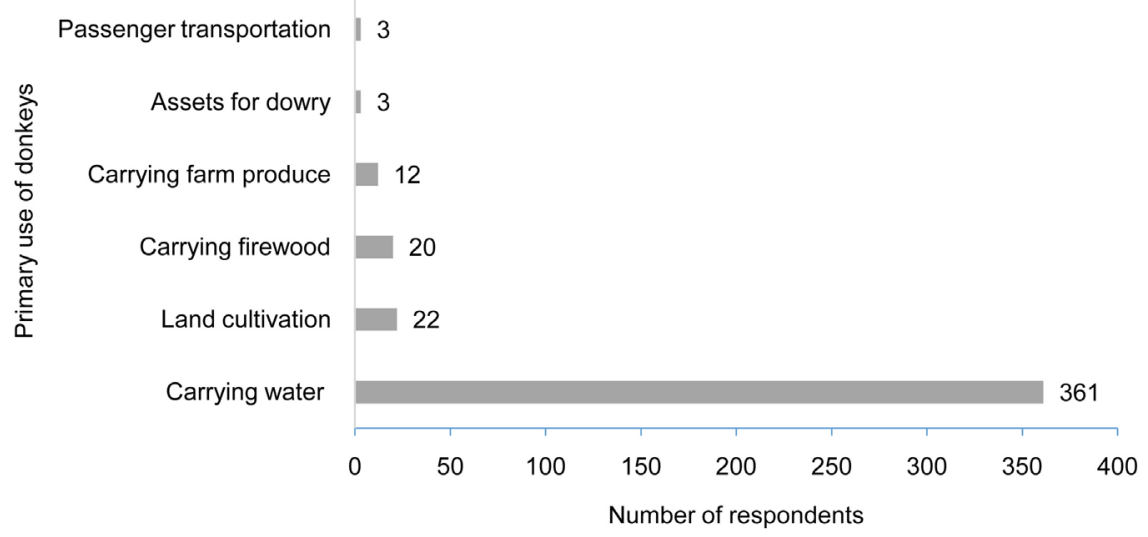

Figure 1. Primary uses of donkeys.

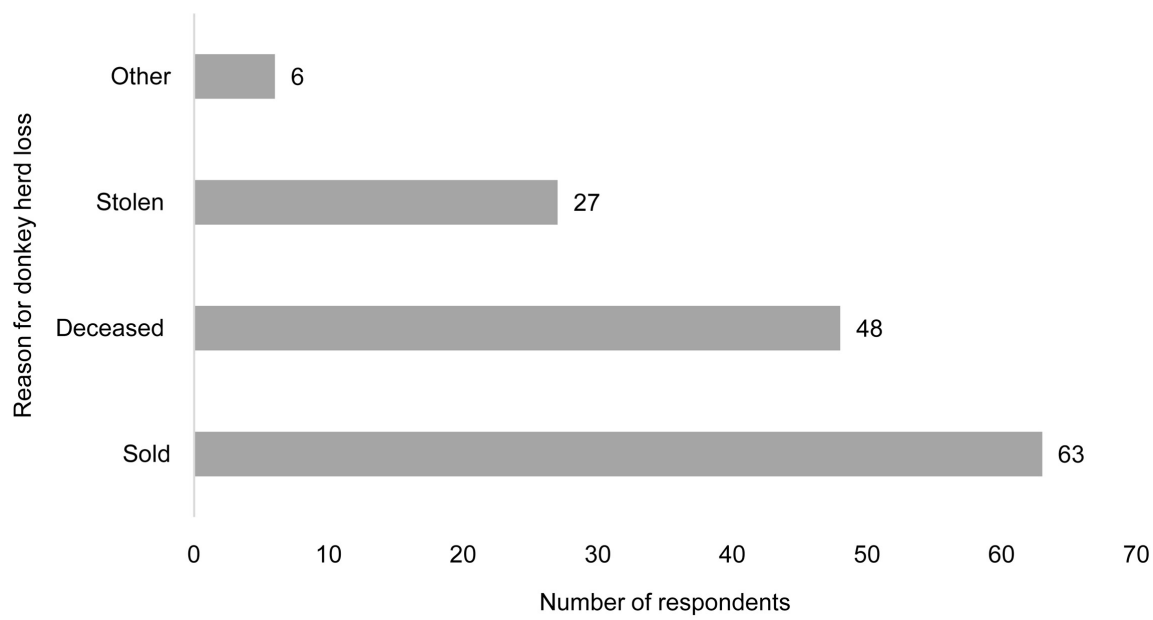

Figure 2. Reasons for decrease in herd number. Factors which contributed to donkey deaths were believed to be unrelated to the donkey hide trade.

and $28.8 \%$ reported a decrease. When asked how the donkey hide trade had effected community members with disabilities (who rely on donkeys to conduct their daily chores), the primary effect reported was that they had to rely on well-wishers to undertake their chores (62.5\%) (Figure 3). Increased money spent on the transportation of farm produce, water and firewood was the most frequent effect of the sale and/or theft of donkeys on household activities (Figure 4).

\subsection{FGDs and KIIs (Qualitative Data)}

Most of the FGD participants were farmers (65.6\%), followed by those who work in transport (8\%) and business (6.7\%).

\subsubsection{Awareness, Demand and Participation in the Donkey Hide Trade} The majority of FGD participants $(60.7 \%, n=136)$ and KII participants $(92 \%$, $n=34$ ) were aware of the donkey hide trade. All FGD participants reported that they had the freedom to participate in the donkey hide trade with no restriction 


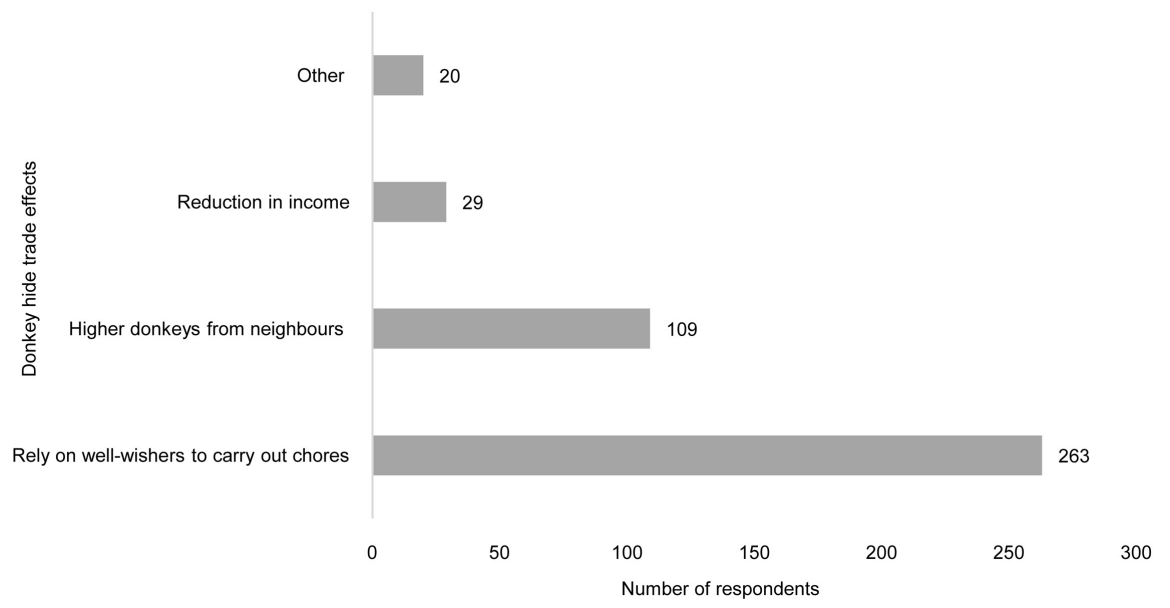

Figure 3. Effects of donkey sale and/or theft on community members with disabilities who use donkeys for their daily activities.

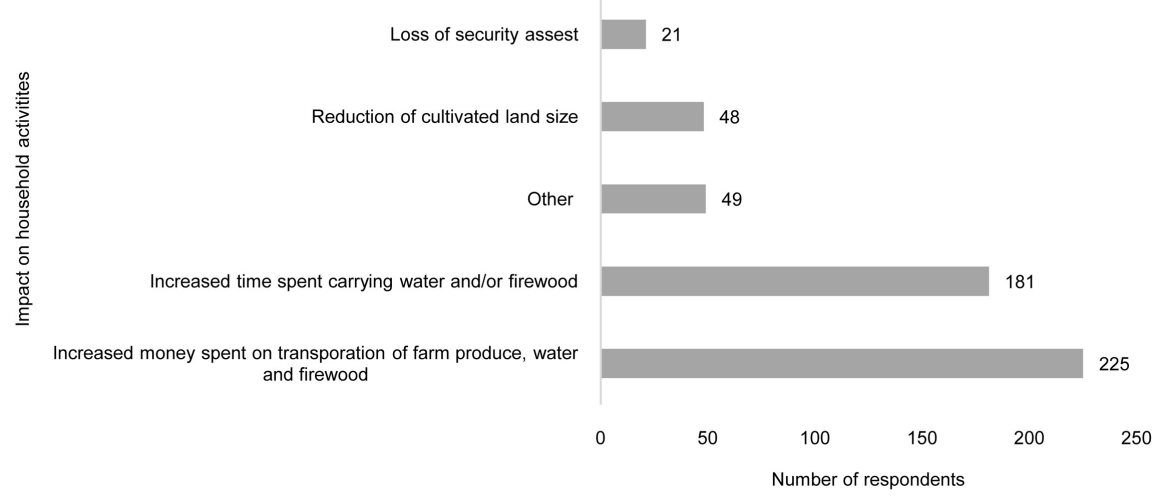

Figure 4. Effects of donkey sale and/or theft on household activities. Note that some participants gave more than one response.

at all. The size, sex and strength of the donkey were reported to be the main indicator for sale. Some FGD participants $(22.2 \%, n=58)$ suggested that they were not comfortable selling their donkeys, however family situations and a need for instant cash had drove them to it. In Narok, it was reported that some middlemen visit households asking them to sell their donkeys when they least wanted to. The majority of both FGD and KKI participants said that men had control on the sale and purchase of donkeys (as heads of the household).

Policies and laws governing the donkey hide trade were viewed as being weak. Only $37.5 \%,(n=84)$ of FGD participants and $16.2 \%,(n=6)$ of KII participants agreed that there was legislation in place to govern donkey trading. The majority of government officials and small holder farmers reported to be in support of controlling or in some cases banning the trade of donkey hides.

A high proportion of FGD $(51.3 \%, n=153)$ and KII participants $(64.9 \%, n=$ 24) reported that in recent years the demand for donkeys for the hide trade had increased and there is very minimum supply. The majority of respondents indicated that the rate of donkey theft had increased in their community, and that 
the security of donkey owners had been compromised due to the increase in demand.

"Generally community members do not have adequate knowledge on donkey trade. As for me I sell it alone, because there is a fixed market price and sometimes I sell at a loss because traders give various reasons to lower my asking price, which I end up accepting because of the pressing needs", Kirinyaga resident, FGD 2.

\subsubsection{Effects of the Donkey Hide Trade on Food Security and Livelihoods} Responses from the FGDs $(67.4 \%, n=151)$ indicated that after the loss/sale of donkeys a noticeable reduction in available food to households had been noticed. This was attributed to a reduction in income that was originally generated from commercial activities involving the use of donkeys. Likewise $45.9 \%$ ( $n=$ 17) of KII participants believed that food security had been compromised. In addition, a reduction in available donkeys meant that households were unable to undertake farming activities such as ploughing with ease, further contributing to food insecurity. As a result some participants reported that a lack of food had driven them to sell their donkeys to generate cash to purchase food. In contrast a small number of FGD participants reported that there was plenty of food in their communities and that the donkey hide trade had not had an effect.

"In this community there are times when there is not enough food at home and my family members sometimes skip meals. Donkeys become handy because someone can use their labour for commercial activities to make money to buy food. So when they are sold, the households are greatly affected since they lose a donkey which they depend on for income generating activities and hence become food insecure". Kitui Resident, FGD 3.

As a result of the loss of donkeys some FGD participants stated that they have had to use expensive substitutes such as motorbikes or have had to carry water and firewood themselves, causing back and related health problems for some women.

Prior to the reduction in donkeys due to sale/theft most of the households reported that they generated extra income by hiring out their donkeys to transport farm produce, water and firewood. However, following the loss of their donkeys many have been forced to hire transport to take their produce to the market, which has resulted in a loss of income. In contrast some FGD participants felt like their lives had improved after selling their donkeys as they were able to use the earnings to buy motorbikes to be used as boda boda (motor cycle taxi).

People with disabilities (term referring to problems such as impairment, activity limitation or participation restrictions that indicate negative aspects of functioning) and the elderly in the community where reported to be effected financially and by having reduced mobility as a result of the loss/sale of donkeys. Households reported that elderly and vulnerable people are becoming increasingly dependent on relatives to provide them with food and other necessitates. 
Some FGD participants $(62.9 \%, n=141)$ reported that prior to the reduction in available donkeys they used the money they had earned from providing transport services to pay their children's school fees; but now they are unable to pay the fees. Some participants said that in the past they had sold their donkeys to raise instant cash to pay school fees. Similarly $43.3 \%,(n=97)$ of FGD respondents indicated that they would comfortably sell their donkeys in case of health emergencies and to pay medical bills. A few reported that they had previously sold donkeys or their hides for cash to clear medical bills.

"My children can never miss education if I have donkeys. I will just sell one and take my children to school. Therefore, education is influenced positively by donkey trade", Narok resident, FGD 4.

Women use donkeys to transport water, farm produce and goods from the market, it was reported by $54.5 \%(n=122)$ of FGD participants and a small percentage of KII participants $(10.8 \%, n=4)$ that loss of donkeys as retracted progress back for women who depend heavily on donkeys for their livelihoods.

\section{Discussion}

We provide an initial insight into the role of donkeys in the livelihoods of small holder farmers in Kenya, and the potential effects of the donkey hide trade. Our study demonstrates that small holder farmers do rely on donkeys for both domestic chores and commercial activities. Furthermore, a large proportion of household survey participants interviewed indicated that as a result of the donkey hide trade their initial income had increased. However, due to the loss of donkeys many were required to spend more money and time on the transportation of farm produce, water and firewood. Qualitative data gained through FGDs and KIIs revealed a deeper understanding of the consequences of the loss/sale of donkeys. With the primary consequence being a lack of available food, which in some instances further contributed to a household's decision to sell their donkeys (for an instance boost in cash). These results suggest that due to the known increased price of donkeys [2] and the reported decrease in the global donkey population [2] [20] it is likely that the trade (including the breeding and selling) of donkeys to meet consumer demand for ejiao is an unsustainable livelihood option long-term for small holder farmers.

\subsection{Livelihoods: The Role of Donkeys and Effects of the Donkey Hide Trade}

A large proportion of household survey respondents used their donkeys for domestic chores only (49.4\%) and the primary activity that people used their donkeys for was carrying water (85.7\%). This is consistent with previous studies that report the important role that donkeys play in carrying water in rural communities in many African countries [4] [21].

When household survey participants were asked if the number of donkeys in their herd had changed within the last two years $32.5 \%$ reported an increase, 
$34.2 \%$ reported a decrease and the remainder said that there had been no change. Of those who stated a decrease the majority (43.8\%) attributed this decrease to donkeys being sold. This finding is further supported from the FGDs and KIIs, whereby a large proportion of respondents reported that demand for donkeys for the hide trade had increased in recent years and that currently there is a minimal supply. Exploration into the factors which contributed to the household heads' decision to sell their donkeys were explored during the FGDs. Reasons for selling donkeys were centred on an immediate need for cash to pay for medical bills and/or school fees. Therefore, the immediate need to cover such expenses was prioritised by households ahead of the long-term value that donkeys have to the livelihoods of households. It is possible that the rapid escalation of the donkey hide trade has fueled options for owners to sell their donkeys quickly and for a reasonable price. This was further collaborated with some FGD and KII participants reporting that in Narok middlemen have been witnessed visiting households to ask household heads to sell their donkeys further supporting this assumption.

When household survey respondents were asked if the donkey hide trade had impacted upon their income, 57\% described an effect, of those $64.6 \%$ believed that their income had increased. This is contradictory to the detailed responses gained during the FGDs whereby the sale/loss of donkeys was reported to cause a reduction in available food supply (attributed to a loss of income). This may be because the instant cash gained was reported during the household surveys, but in depth responses from the FGDs highlight the longer term income effects (particularly on food security). Our data suggesting that participation in the donkey hide trade can provide a quick income boost has also been witnessed during the trade in wildlife species. Historically, trade in wildlife has presented itself as a lucrative and attractive livelihood option to poor communities because of its low technical and economic entry requirements, and it can provide opportunities for a quick gain in cash [22].

The International Union for Conservation of Nature (IUCN) considers the use of a species to be sustainable if it does not reduce the potential for future use of that species for future generations [23]. It's believed that the trade in wildlife is more likely to positively impact livelihoods when species have a high resilience to harvest [14]. If populations are being poached at an unstainable rate, this may then create a dependency on an unsustainable livelihood [14]. The demand for ejiao is currently increasing [2] [20], and it's reported that supply cannot meet the demand, resulting in the global donkey population being put at risk [2] [20]. Therefore, the trade in donkey hides is unlikely to be a sustainable livelihood option for smallholder farmers; also the demand for donkey hide products has increased the purchase price of donkeys [2]. In light of this, it's possible that those selling their donkeys may not be able to replace them in the future, thus impacting traditional livelihood strategies which donkeys are integral to.

The effect of donkey loss on household's abilities to carry out their daily activ- 
ities was assessed. When household survey participants were asked how the donkey hide trade had affected community members with disabilities; the majority $(62.5 \%)$ reported that people with disabilities had to rely on well-wishers to carry out their daily chores. This was further supported through the FGDs, whereby a loss of income was the primary described effect of the sale/loss of donkeys, on the elderly and people with disabilities. It should be noted that all participants in the household surveys, FGDs and KIIs were asked about the effects of donkey loss on vulnerable groups (regardless of if they had a disability themselves or not); further research could focus on surveying individuals considered to have a disability to gain perspectives of their own experiences.

Household survey respondents expressed that due to loss of donkeys many (53.4\%) were spending an increased amount of money on the transportation of farm produce, water and firewood. Also $43 \%$ reported that they were required to spend more time carrying water and firewood. During the FGD's some respondents also described a particular negative effect on women who rely heavily on donkeys to transport water, farm produce and goods. These consequences further support the assumption that long-term the loss of donkeys will presumably be detrimental to small holder farmers livelihoods and well-being (regardless of the short-term gain in income), with a particular burden being faced by women.

\subsection{Limitations and Recommendations}

This is the first peer-reviewed study we are aware of that has explored the impact of donkey loss/sale due to the donkey hide trade on the livelihoods of small holder farmers. This study was designed to capture quantitative and qualitative data at particular moment in time, and gain community members perspectives on how the donkey hide trade has changed/affected their livelihood strategies in recent years. The data does strongly suggest that the trade in donkey hides is unsustainable for households in Kenya who have traditionally relied on them for their livelihoods. Currently there is little legislation in place to govern the trade in donkey hides. If policies and legislation are introduced and enforced in relation to the trade, future research could explore for impact such legislation may have on household's livelihoods. This would help inform future actions which may be needed to regulate the donkey hide trade. Although this study was concerned with Kenya, we suggest that it may be useful for future studies to explore the effects of the donkey hide trade on livelihoods in other African countries where the trade is known to take place. Respondents reported that people with disabilities (who had lost their donkeys) had to rely on well-wishers to carry out their daily activities and that household members were required to spend more of their own time carrying water, fire wood and farm produce and/or more money on this activity. Aside from the economic effects, it would also be beneficial to determine other potential long term effects on the well-being and health of individuals.

Our study indicates that community members believe that there is a lack of 
sufficient knowledge available on laws governing donkey trade and pricing, and during KIIs government leaders and country government representatives indicated that there are no clear policies on the donkey hide trade. This highlights that more legislation and enforcement of existing policies are needed in relation to all aspects of the trade to protect both people and animals. This is something that international organizations working on advocacy initiatives centred on the donkey hide trade should be working towards.

The donkey hide trade is multifaceted, and is driven by the demand from Chinese consumers. The traditional Chinese view is that wildlife is a resource to be exploited and should not necessarily be protected because of its intrinsic value [13]. Previous research has been conducted to understand Chinese consumer's attitudes and perceptions around use of wildlife parts in traditional medicine products [24] [25] [26]. As far as we are aware there are no published studies specifically looking at beliefs and attitudes centered on the consumption of ejiao. Research aimed at understanding drivers for the demand of ejiao, and the demographics of those who consume it will aid campaigning and educational initiatives aimed at reducing the demand.

Various attempts have been made to try and reduce the impact that the demand for traditional medicine products have on wild animal population numbers [11]. For example, the Chinese government has put 161 wild animal species used in TCM on the Key National Protected Wild Animal List [12]. In addition, research into synthetic alternatives has been conducted [27]. In the case of bear bile scientists have succeeded in chemically synthesizing UDCA (a type of acid in bear bile which gives bear bile its proposed medicinal benefits) [27]. It has been reported that large quantities of synthetic UDCA is consumed in China, Japan and South Korea [27]. Non-governmental organizations and the media play a vital role in reducing the demand for traditional medicine products which use wild animal derivatives by raising public awareness [27]. Similar approaches could be taken to reduce the demand for products derived from donkey hide.

The welfare concerns centred on the breeding, transportation and slaughter of donkeys were not investigated in this study. However, findings from an unpublished paper have reported animal welfare concerns during slaughter, at loading and offloading zones and at holding pens at one of the slaughter houses in Kenya [18]. As is the case for all species reared for the traditional medicine market, the rearing of animals for the purpose of producing traditional medicine products raises a number of ethical concerns. We suggest that more work is done to understand the welfare issues associated with the trade.

\section{Conclusion}

Donkey hides have been used for centuries in Traditional Chinese medicine. However, following similar trends for an increased demand for products made from wildlife derivatives [28], in recent years the demand for donkey hides has escalated. The donkey hide trade is unlikely to be a sustainable livelihood option 
for rural communities in Kenya. This study provides an initial insight into the effects of the donkey hide trade on livelihoods of small holder farmers in Kenya, and has the potential to aid future intervention programmes around reducing the demand for donkey hide products and safeguarding livelihoods. If donkey population numbers are indeed decreasing, further understanding about the effects of this trade on livelihoods, and the conservation status of donkeys are needed now and additional legislation should be introduced and enforced. Although, this study did not explore any potential animal welfare and/or ethical implications of the breeding, transportation and slaughter of donkeys for the trade, research and further understanding of this is also needed, which can then be used for advocacy initiatives.

\section{Acknowledgements}

We would like to thank Brooke for their financial support of this study, and Polly Compston for her inputs into the methodological design of the study and constructive comments on the manuscript.

\section{Conflicts of Interest}

The authors declare no conflict of interest.

\section{References}

[1] Valette, D. (2015) Invisible Workers: The Economic Contributions of Working Donkeys, Horses and Mules to Livelihoods.

[2] McLean, A.K. and Gonzalez, F.J.N. (2018) Can Scientists Influence Donkey Welfare? Historical Perspective and a Contemporary View. Journal of Equine Veterinary Science, 65, 25-32. https://doi.org/10.1016/j.jevs.2018.03.008

[3] Fernando, P. and Starkey, P. (2004) Donkeys and Development: Socio-Economic Aspects of Donkey Use in Africa. In: Donkeys, People and Development, a Resource Book in the Animal Traction Network for Eastern and Southern Africa (ATNESA). ACP-EU Technical Centre for Agricultural and Rural Cooperation (CTA), Wageningen, The Netherlands, 459-508.

[4] Valette, D. (2014) Invisible Helpers. Women's Views on the Contributions of Working Donkeys and Mules to Their Lives. Key Findings from Research in Ethiopia, Kenya and Pakistan.

https://www.cabdirect.org/cabdirect/abstract/20143204172

[5] Donkey Sanctuary (2017) Under the Skin: The Emerging Trade in Donkey Skins and Its Implications for Donkey Welfare and Livelihoods.

https://www.thedonkeysanctuary.org.uk/what-we-do/issues/donkey-meat-skin-and -milk?gclid=EAIaIQobChMIhPP6iamW5AIVhbTtCh3F4g2kEAAYASAAEgKY5vD _BwE\&gclsrc=aw.ds

[6] Curran, M.M. and Smith, D.G. (2005) The Impact of Donkey Ownership on the Livelihoods of Female Peri-Urban Dwellers in Ethiopia. Tropical Animal Health and Production, 37, 67-86. https://doi.org/10.1007/s11250-005-9009-y https://link.springer.com/article/10.1007/s11250-005-9009-y

[7] Doumbia, A. (2014) The Contribution of Working Donkeys to the Livelihoods of 
the Population in Mali. Proceedings of the 7 th International Colloquium on Working Equids, London, 1-3 July 2014.

[8] Kriel, G. (2017) Donkey Production: Great Economic Opportunity or Potential Minefield? Farmer's Weekly, 2017, 36-40.

https://journals.co.za/content/journal/10520/EJC-aafee36ca

[9] Chronicle, T. (2016) Botswana Govt Issues Permits for Donkey Meat Export. http://www.chronicle.co.zw/botswana-govt-issues-permits-for-donkey-meat-export

[10] Mainka, S.A. and Mills, J.A. (1995) Wildlife and Traditional Chinese Medicine: Supply and Demand for Wildlife Species. Journal of Zoo and Wildlife Medicine, 26, 193-200. https://www.jstor.org/stable/20095462

[11] Liu, Z., Jiang, Z., Fang, H., Li, C., Mi, A., Chen, J. and Li, F. (2016) Perception, Price and Preference: Consumption and Protection of Wild Animals Used in Traditional Medicine. PLoS ONE, 11, e0145901. https://doi.org/10.1371/journal.pone.0145901

[12] SINO-TCM (China National Group Corporation of Traditional and Herbal Medicine) (1995) Traditional Chinese Medicine Resources in China.

[13] Zhang, L., Hua, N. and Sun, S. (2008) Wildlife Trade, Consumption and Conservation Awareness in Southwest China. Biodiversity and Conservation, 17, 1493-1516. https://link.springer.com/article/10.1007/s10531-008-9358-8 https://doi.org/10.1007/s10531-008-9358-8

[14] Cooney, R., Kasterine, A., MacMillan, D., Milledge, S., Nossal, K., Roe, D. and Sas-Rolfes, M. (2015) The Trade in Wildlife: A Framework to Improve Biodiversity and Livelihood Outcomes.

[15] Gao, Y., Stoner, K.J., Lee, A.T. and Clark, S.G. (2016) Rhino Horn Trade in China: An Analysis of the Art and Antiques Market. Biological Conservation, 201, 343-347. https://doi.org/10.1016/j.biocon.2016.08.001

[16] Saif, S., Rahman, H.T. and MacMillan, D.C. (2018) Who Is Killing the Tiger Panthera tigris and Why? Oryx, 52, 46-54. https://doi.org/10.1017/S0030605316000491

[17] Katuwal, H.B., Neupane, K.R., Adhikari, D., Sharma, M. and Thapa, S. (2015) Pangolins in Eastern Nepal: Trade and Ethno-Medicinal Importance. Journal of Threatened Taxa, 7, 7563-7567. https://doi.org/10.11609/JoTT.o4202.7563-7

[18] Garden Veterinary Services LTD (2017) A Survey of Donkey Trade and Slaughter Practices in Kenya, the Case of Narok County.

[19] OIE (2019) Equine Influenza, Nigeria. http://www.oie.int/wahis_2/public/wahid.php/Reviewreport/Review?page_refer=M apFullEventReport\&reportid=29135

[20] OIE (2019) In Light of Recent Events, OIE Highlights Activities to Protect Donkey Health and Welfare. https://rr-africa.oie.int/en/news/20190503.html

[21] Marshall, K. and Ali, Z. (1997) Gender Issues in Donkey Use in Rural Ethiopia. In: Donkeys, People and Development, a Resource Book of the Animal Traction Network for Eastern and Southern Africa (ATNESA), Wageningen, The Netherlands, 62-68. http://www.atnesa.org/donkeys/donkeys-marshall-gender-ET.pdf

[22] Neumann, R.P. and Hirsch, E. (2000) Commercialisation of Non-Timber Forest Products: Review and Analysis of Research. https://www.cifor.org/ntfpcd/pdf/MgNTFP3.pdf

[23] Cooney, R. (2007) Sustainable Use: Concepts, Ambiguities, Challenges. Meeting of the IUCN Species Survival Commission's Sustainable Use Specialist Group Strategic Planning Meeting, White Oak Plantation, 10-13 July 2007, 1-76. 
https://www.iucn.org/backup_iucn/cmsdata.iucn.org/downloads/whiteoakmtgfinal backgroundjuly07.pdf

[24] Davis, E.O., O’Connor, D., Crudge, B., Carignan, A., Glikman, J.A., Browne-Nuñez, C. and Hunt, M. (2016) Understanding Public Perceptions and Motivations around Bear Part Use: A Study in Northern Laos of Attitudes of Chinese Tourists and Lao PDR Nationals. Biological Conservation, 203, 282-289.

https://doi.org/10.1016/j.biocon.2016.09.009

[25] Liu, Z., Jiang, Z., Yang, A., Xu, B., Fang, H., Xie, Z. and Zeng, Y. (2017) Attitudes toward Bile Extraction from Living Bears: Survey of Citizens and Students in Beijing. Journal of Applied Animal Welfare Science, 20, 205-218. https://doi.org/10.1080/10888705.2017.1283990

[26] Gratwicke, B., Mills, J., Dutton, A., Gabriel, G., Long, B., Seidensticker, J. and Zhang, L. (2008) Attitudes toward Consumption and Conservation of Tigers in China. PLoS ONE, 3, e2544. https://doi.org/10.1371/journal.pone.0002544

[27] Feng, Y., Siu, K., Wang, N., Ng, K.M., Tsao, S.W., Nagamatsu, T. and Ong, Y. (2009) Bear Bile: Dilemma of Traditional Medicinal Use and Animal Protection. Journal of Ethnobiology and Ethnomedicine, 5, 2. https://doi.org/10.1186/1746-4269-5-2

[28] Zhang, L. and Yin, F. (2014) Wildlife Consumption and Conservation Awareness in China: A Long Way to Go. Biodiversity and Conservation, 23, 2371-2381. https://doi.org/10.1007/s10531-014-0708-4 


\section{Supplementary Material 1}

\section{Household survey questionnaire}

Name of the respondent.

Mobile number of respondent....

County.....

Name of the enumerator.

GPS.

Date.

\section{Demographic Characteristics}

1) What is the gender of the respondent?

o Male

o Female

2) What is your age of the respondent in complete years'........

3) What is your relationship to the household head:

○ Head of household

- Spouse

- Son

○ Daughter

○ Parent

- Sibling (Brother/Sister)

○ Extended family e.g. cousin

4) What is your level of educational of the household head;

o No formal education

o Primary

o Secondary

o Tertiary

o Adult education

o Vocational Education

5) What is your level of educational of the household head in years .......

6) What is the main occupation of the household head?

o Farming (own farm/family)

o Employed for farm work

o Employed in other sector (public/private/NGO)

o Self-employed (business)

o Others (Specify)

7) What is the level your household average monthly income in Kenya Shillings?

8) What is the level your household average monthly expenditure for food?

\section{Farming and Enterprises}

9) Do you own the land where you farm your crops or rear livestock;

o Yes

o No 
10) If Yes in 8 , above, do you have land title deed?

o Yes

o No

11) What is the size of your land in acres?

12) Which type of crops grow or livestock do you rear? Please list the crops grown on your farm

\begin{tabular}{cc}
\hline & Crops/Livestock \\
1 & Crops: \\
2 & Tick \\
3 & Pegetables and fruits \\
4 & Maize \\
5 & Cotton \\
6 & Rice \\
7 & Wheat \\
8 & Sugarcane \\
& Other $\quad$ Livestock: \\
9 & Donkeys \\
10 & Cows \\
11 & Sheep and goats \\
12 & Pigs \\
13 & Poultry \\
15 & Fish \\
\hline
\end{tabular}

13) How do you cultivate your parcel of land?

o Use tractor

o Use hoe

o Use donkeys/mules

o Others (Specify)

14) Are the crops you grow or livestock you rear enough for your domestic consumptions?

o Yes

o No

15) If Q14 is Yes, what do you do with the surplus harvest or livestock product produced?

o Sell

O Keep for future use

16) If Q14 is No, what are reasons?

17) Do you have a market for the crops you grow/ animals you rear?

o Yes 
O No

18) If Q17 is Yes, how far is your closet market in KMs?

19) How much do you averagely earn in a year from sale or crops/livestock?

o Less Ksh 10,000

o Ksh 10,001 - Ksh 30,000

o Ksh 30,001 - Ksh 50,000

o Ksh 50,001 - Ksh 70,000

o Ksh 70,001 and above

20) For how many years have you been farming the above crops and rearing the livestock?

21) In the last 5 years have you experienced changes in rainfall patterns?

o Yes

o No

22) If $Q 21$ is Yes, how have you been coping?

o Planting drought resistant crops

o Diversifying crops/livestock breeds

- Improving on cultivation practices

o Reducing the livestock herds

o Selling livestock

o Others specify

Donkey Trade and Livelihood Options

23) Do you rear donkeys as part of your livestock's?

o Yes

o No

24) If Q23 is Yes how many donkeys do you currently have?

25) What are the main uses of donkeys in your household?

o Used in unpaid household activities

o Used in commercial activities within the village

o Used in both commercial and household activities

o Others specify

26) What are the main activities that your donkeys normally do?

o Land Cultivations

o Carrying water

o Carrying farm produce

o Carrying firewood

o Passenger transportation

o Assets for dowry

o Others specify.

27) What are the main uses of donkeys in your community?

o Land Cultivations

o Carrying water

- Carrying farm produce

o Carrying firewood 
- Passenger transportation

o Assets for dowry

o Others specify

28) Are you aware of donkey trade in your community?

o Yes

o No

29) If Q28 is Yes how long has it been operating in your community?

o Less than 1 year

0 Between 1 and 2 years

o More than two years

30) Have you ever participated in the donkey trade in the last 12 months?

o Yes

o No

31) If Q30 is Yes what activity were you doing?

o Buying donkey

o Selling donkey

o Others (Specify)

32) What is an average price of live donkey in your community?

33) What is the contribution of donkey trade to household income?
○ High
- Moderate

○ Low

34) What is the contribution of donkey trade to your household food and nutritional security status?

○ High

- Moderate

- Low-Nothing significant

35) Who makes decision to buy or sell donkey in your household?

o Husband

o Wife

o Children

o Others (Specify)

36) Who keeps the money proceeds from the sale of a donkey in your household?

o Husband

o Wife

o Children

o Others (Specify)

37) Who always handles/uses the donkeys in your household?

o Husband

o Wife

o Young male children

o Young female children 
o Older men servant

o Older women servant

o All

38) Who owns donkey(s) in your household?

o Husband

o Wife

o Young male children

o Young female children

o Older men servant

o Older women servant

o All

39) How has your donkey herd changed in the last 2 years?

o Increased

o Decreased

- Constant/Same

40) If Donkey herd increased what were the reason?

o Bought new donkey(s)

o New young donkey(s)

o Others (Specify)

41) If donkey herd decreased what were the reasons?

o Donkey sold

o Donkey stolen

o Donkey died

o Others (Specify)

42) What is the frequency of using donkey(s) for farming and non-farming activities?

o Used every day

o Used every two days

o Used once a week

o Used every two weeks

o Used once a month

43) Have you ever participated in the donkey hide trade in the last 12 months?

o Yes

o No

44) If Q43 is yes, who buys the donkey hides in your community?

o Traders/middlemen

o Donkey slaughter houses

o Community members

45) What is the average price of a donkey hide in your community? Ksh.

46) How did you utilize the money earned from selling donkey(s) hides?

o Purchased another donkey

o Purchased a cow 
o Purchased a motor bike

o Purchased land

o Purchased farm inputs

o Paid school fees

o Purchased food

- Purchased household accessories/assets

o Others (Specify)

47) As a result of the donkey trade, how do you rank the livestock you own by importance?

Where 1 is very important and 3 less important

\begin{tabular}{ccc}
\hline No. & Livestock & Rank \\
\hline 1 & Donkeys & Cows \\
2 & Sheep and goats \\
3 & Pigs \\
4 & Poultry \\
5 & Fish \\
6 & Donkeys \\
7 & Cows \\
9 & Sheep and goats \\
11 & Pigs \\
12 & Poultry \\
\hline
\end{tabular}

48) If your donkey(s) was stolen or sold how are you now carrying out your farming and non-farming activities?

o Hire neighbours donkey

o Hire a motor bike

o Hire a car

o Carry on our backs

- Left farming to concentrate on other business

o O Others (Specify)

49) In the case where persons with disability used/relied on donkeys for their daily activities, how has this trade affected their lives?

o Rely on well-wishers to undertake their activities

o Hire donkeys from neighbours

o Reduced their incomes

o Others (Specify)

50) As a result of donkey(s) sale or donkey theft who shoulders the burden for household chores/farming activities?

o Husband

o Wife 
o Young male children

o Young female children

o Older men

o Older women

o All

51) If you hire a means of transport for carrying out your farming and non-farming produce, how much do you pay each time?

52) How has donkey trade affected your income streams?

o Increased my income

o Decreased my income

53) If Income from farming and non-farming activities decreased, how are you copping with the change?

o Go to provide labour to other farms

- Engaged in small entrepreneurship activities

o Others (Specify)

54) In your community, are donkeys used as collateral for securing loan (s)/credit?

o Yes

o No

55) As a smallholder farmer, given another chance would you agree to sale your donkey(s)?

o Yes

o No

56) If Q55 is No why?

57) As a smallholder farmer how can you rate the donkey trade in your community?

o Very bad

o Bad

o Neither good/bad

o Good

o Very good

58) As a smallholder farmer how concerned are you with donkey theft practice in your community?

o Not concerned

o Okay with it

o Very concerned

59) If your donkey was stolen, has it affected you emotionally?

o Yes

o No

60) As a result of donkey sale or donkey theft how has this impacted your household' activities?

o Spend more time carrying water and or firewood

o Reduced the size of cultivated land 
o Increased spending of money for transportation of farm produce, water, firewood etc.

o Lost a credit security asset

o Affected payment of dowry

o Others (Specify)

61) If the size of cultivated land has reduced, how has this affected your household food security and nutritional status?

o We now have few food stock for consumptions

o We now skip meals

o It is difficult to transport harvested crop and hence rot in the fields

o Other specify

62) What are the views of smallholder farmers in your community on how to reduce or managed donkey trade in your community?

o Licence all donkey traders

- Educated farmers on donkey trade

o Educate farmers on the importance of donkeys for the livelihoods

o Support farmers with breed improvement for donkeys

o Ban donkey trade partially

o Ban donkey trade fully

o Others (Specify)

63) In your community are you aware of policies/laws governing trade in donkeys?

o Yes

o No

64) If Q63 is Yes, who enforces the laws/policies?

o County government

o National government

o NGOs/animal welfare groups

o Farmers

o Others (Specify)

65) Please list any other concerns on how the donkey hide trade has affected farmers in your community? 


\section{Supplementary Material 2}

\section{Focus group discussion questions}

1) Do smallholder farmers in your community have donkeys (s)? What are the different uses/benefits of donkey(s) in your community? In which sector/activity are the donkeys mainly utilised in your community?

- How do women use donkey(s) in your community?

- How do men use donkey(s) in your community?

- How do agricultural workers/famers use donkey(s) in your community?

2) On average how many donkeys are there in your community? If there is variation in number of donkeys over the last 5 years in your community, what could be the reasons? On average how many donkeys does a farmer own in your community? On average what is the percentage of donkey(s) owners in your community?

3) In your community are donkeys used commercial purposes, if yes list the purposes? If donkeys are commercially used, how much income do you earn per month? And who gets priority to use donkey(s) this way in your community? If donkeys are used for household activities, list the main activities?

4) Are people/smallholder farmers aware of the existence of donkey trade in your community? Is this trade widely known in your community? What is the general feeling of people in your community about this donkey? What could be the reasons that could have influence donkey owners to sell their donkeys given the benefits it serves?

5) Are small holder farmers/community members free to participate in donkey trade? If No why?

6) On general terms are small holder farmers/community members have adequate knowledge on donkey trade? If No, what information do they feel is lacking?

7) What is the average price of a mature donkey in your community? What is the difference between the average prices of a live donkey and hide in your community? If the price is not uniform, what could have contributed to the changes?

8) Are there traders/middlemen buy donkeys or donkey hides in your community? How do they source for the donkeys/hides?

9) What are the general community views on donkey trade in your community? Are specific issues that concern majority of community members?

10) Who mostly makes decision on whether to sell or use donkey/donkey hides in your community? What are the women roles in terms of donkey trade? Who make decision on sales proceeds from donkey trade?

11) How has the sale/loss of donkey(s) affected the following activities in your community?

12) How has the donkey trade affected/support the following issues in your community among the small holder farmers?

13) How has the donkey trade affected the vulnerable groups in your community like person with disability and elderly? How are they coping as a result of sale/loss of a donkey?

14) Are there persons/groups in your community who are advocating for the 
control/promotion of donkey trade in your community? If yes provide names of lobby groups

15) Are community members aware of existence of law/policy to guide the use of donkeys and its trade? Explain

16) Do community members need additional information/training on donkey trade? If yes what information/trainings do community member's feel are priority?

17) Is there a farmer's group organization that deals with donkey trade and marketing issues to support small holders in your community? If yes, what services or benefits are accrued to the members?

Key informant interview questions

1) Does the County have Policy/Guideline? If yes, does the policy/guideline include donkeys? If No is there plan to develop such policy/guideline to support donkeys? Explain

2) How has the current donkey hide business affected the small holder farmers in your county? Explain especially effect on women farmers? Or other marginalized groups e.g. ethnic groups or vulnerable groups etc.

3) Are there any strategies in place related to the trade in donkey hides? Has this affected the extension mandate to farmers, or how the trade in is monitored?

4) Are there instances of donkey theft reports? If yes how frequent are the reports? Do they donkeys or skin them for hides? How has the County handled this problem?

5) What is the future of donkey hide trade on your county? Explain 